\title{
Relationship between the Functional Oral Intake Scale and Self-efficacy Scale among Patients with Cancer: A Cross-sectional study
}

Yuhei Matsuda ( $\nabla$ yuhei@med.shimane-u.ac.jp )

Shimane University https://orcid.org/0000-0001-8922-3582

Masaaki Karino

Shimane University

Takahiro Kanno

Shimane University

\section{Research article}

Keywords: Functional Oral Intake Scale, Self-efficacy Scale for Advanced Cancer, Oral Health-related SelfEfficacy Scale for Patients with Cancer, Cancer; Dysphagia, Nutrition

Posted Date: April 30th, 2020

DOI: https://doi.org/10.21203/rs.3.rs-23518/v1

License: (c) (i) This work is licensed under a Creative Commons Attribution 4.0 International License. Read Full License 


\section{Abstract}

Background: A few studies suggest that self-efficacy pertaining to swallowing ability can lead to dysphagia. Therefore, this cross-sectional study verified the relationship between oral health-related selfefficacy and dysphagia severity during cancer treatment.

Methods: Participants included patients undergoing treatment for cancer at Shimane University Hospital, Shimane, Japan, and those receiving outpatient treatment at the hospital's Oral Care Center between August 2018 and April 2019. In all, 203 participants enrolled in the study and completed the Functional Oral Intake Scale (FOIS), Self-efficacy Scale for Advanced Cancer (SEAC), and Oral Health-related SelfEfficacy Scale for Patients with Cancer (OSEC).

Results: A multivariate analysis showed a statistically significant correlation between the low FOIS score category and the SEAC subscales of Activities of Daily Living Self-efficacy (ADE) (odds ratio 1.04, 95\% confidence interval [Cl] 1.00-1.07) and Symptom Coping Self-efficacy (SCE) (odds ratio 0.61, 95\% [Cl] 0.42-0.88). Based on the Jonckheere-Terpstra test, the SEAC and OSEC scores tended to increase as the FOIS category progressed.

Conclusion: These findings suggest that self-efficacy played an important role in dysphagia and it may affect the severity of dysphagia.

\section{Background}

In patients with cancer, it is highly likely that symptoms such as swallowing dysfunction (dysphagia) and appetite loss become a focus of supportive care [1]. Dysphagia may lead to greater distress for not only the patients with cancer but also their caregiver(s), especially if the intake of fluids and solids is discontinued or withheld [2]. Several factors can cause dysphagia in patients with cancer. It could significantly impact their physical and psychological wellbeing, and its management could become complex and multifactorial [3]. Numerous studies have reported dysphagia and appetite loss in patients with cancer (stomach, colorectal, lung, breast, and head/neck) [4-8]. Moreover, Frowen et al. [7] found that the following proportion of patients with 14 types of cancers reported dysphagic symptoms: any dysphagia (54\%), dysphagia for liquids (20\%), and dysphagia for solids (46\%). Further, significantly more patients with head and neck cancer and significantly fewer patients with breast cancer reported dysphagia; however, there were no differences between other tumor types [7]. Additionally, dysphagia was associated with other symptoms, including taste changes, xerostomia, voice changes, smell changes, thick mucus, difficulty with teeth/dentures, mouth/throat pain, and trismus [7].

Dysphagia can be caused by any one or more of the following conditions: (1) severe neurological impairment (e.g., stroke, myasthenia gravis, and inflammatory myopathies), (2) structural damage (e.g., trauma caused by intubation or malignancies), (3) side-effects of a medication or toxic/drug, (4) presbyphagia, and (5) phagophobia [9]. It can not only lead to malnutrition, weight loss, and aspiration pneumonia but also affect health-related quality of life (HRQoL) and its psychological and social aspects 
[10]. Youssof et al. reported that the severity of dysphagia had stronger associations with the mental rather than physical components of HRQoL in patients with oculopharyngeal muscular dystrophy [11]. The literature suggests that dysphagia may affect an individual on a psychological level, where risks of suffocation, severe coughing, and vomiting may increase anxiety and lower self-esteem [12]. From the social perspective, mealtimes may be very stressful, such that experiences such as visiting a restaurant may not be pleasant anymore $[13,14]$. Furthermore, patients with dysphagia can become isolated, feel excluded by others, and experience anxiety and distress at mealtime [15].

However, dysphagia may not be determined by constitutional and functional factors. For instance, in stroke and laryngectomy patients with dysphagia, psychological aspects, such as self-efficacy, play an important role in rehabilitation and eating habits $[16,17]$. In other words, what patients with dysphagia can or cannot eat is affected by their deglutition self-efficacy.

Bandura proposed that self-efficacy is an individual's expectation regarding the extent to which she/he can implement specific actions that are necessary for producing a specific result [18]. People's selfefficacy beliefs determine their emotions, thoughts, behaviors, and motives. In clinical practice, selfefficacy refers to patients' perceptions of their abilities to take actions required for improving and maintaining their health, such as controlling weight, engaging in physical activity, and controlling alcohol consumption [19-21]. In a prospective cohort study of 100 patients who had experienced either a transient ischemic attack or an ischemic stroke, Brouwer et al. found that baseline self-efficacy, as determined by the patient's responses to questionnaires, was the strongest predictor of his/her intention to adopt a healthy diet $(95 \% \mathrm{Cl}, 0.23-0.75)$ [22].

Self-efficacy can be evaluated by several scales such as the General Self-Efficacy Scale (GSES) and SelfEfficacy for Advanced Cancer (SEAC). Hirai et al. described the SEAC as a scale designed specifically for oncology. It comprises 18 items across three factors (affect regulation self-efficacy, symptom coping selfefficacy, and activities of daily living self-efficacy)[23]. We developed the Oral Health-related Self-efficacy Scale for Cancer Patients (OSEC) in a previous study [24]. The OSEC is a 17-item scale comprising the following five subscales: Oral Function Self-efficacy (OFE; four items), Dental Visits Self-efficacy (DVE; three items), Adverse Effects Self-efficacy (AEE; four items), Symptom Coping Self-efficacy (SCE; three items), and Brushing Habits Self-efficacy (BHE; three items). A randomized controlled trial by Gillham and Endacott proved that preventive intervention, which consisted of providing patients with additional counseling, motivational interviewing, and frequent telephone follow-ups after suffering a minor stroke, enhanced their self-efficacy [25]. Of the 52 patients enrolled in the trial, half received this intervention, while the control group received "conventional care." On an average, patients in the "enhanced secondary prevention group" increased their consumption of fruits and vegetables by 7.6 servings per week, while those in the control group only increased it by 2.0 servings per week $(p=0.03)$, indicating that enhancing self-efficacy had a significant impact on the dietary choices of patients who had experienced a stroke [25]. 
However, only a few studies have explored if self-efficacy related to swallowing ability could lead to dysphagia in patients with cancer. Therefore, in the present cross-sectional study, we examined the relationship between self-efficacy and dysphagia severity during cancer treatment using.

\section{Methods}

This study used the same data set as that used in a previous study [24]. However, the purpose and statistical analysis are different from this cross-sectional study.

\subsection{Participants}

This study included participants from the population of patients with cancer who were being treated at Shimane University Hospital, Shimane, Japan, and who received outpatient treatment at the hospital's Oral Care Center. The inclusion criteria were (1) being treated for cancer at Shimane University Hospital, (2) receiving outpatient treatment at the Oral Care Center, Shimane University Hospital, (3) being aged 20 years or older, and (4) being able to complete the self-administered written questionnaire. The exclusion criteria were (1) currently being treated for a mental disorder and (2) having a history of mental disorder.

Data were collected from August 2018 to April 2019. Participants were recruited using a sequential sampling method.

\subsection{Ethical Considerations}

The medical ethics committee of Shimane University Faculty of Medicine approved this study (approval number 3243). Written informed consent was obtained from the 203 individual participants enrolled in the study.

\subsection{Measurements}

The surveyed items were as follows: patient characteristics (age, gender, body mass index [BMI], alcohol consumption, Brinkman index, number of co-residents, employment), underlying characteristics of solid cancer (primary tumor site, cancer stage, treatment type, number of months since last treatment, Eastern Cooperative Oncology Group Performance Status), and intraoral findings (number of teeth, dentures, brushing times per day, family dentist, dental visit[s] since last year).

\subsubsection{Functional Oral Intake Scale (FOIS)}

Oral intake and nutritional status were assessed using the FOIS. Scores ranged from one to seven, with higher scores indicating better swallowing function (Table 1) [26]. 
Table 1

The Functional Oral Intake Scale (FOIS)

\begin{tabular}{|llll|}
\hline Score & Performance & Implication & Deficit \\
\hline 1 & Aspirates saliva/Tube dependent & Nothing by mouth & Profound \\
\hline 2 & Tube dependent & Nothing by mouth/Minimal trials & Profound \\
\hline 3 & Tube dependent & Full trials by mouth & Severe \\
\hline 4 & Total oral & Single texture trials & Moderate \\
\hline 5 & Total oral & Multiple texture trials & Mild \\
\hline 6 & Total oral & By mouth/restrictions & Minimal \\
\hline 7 & Regular diet & By mouth/No restrictions & None \\
\hline
\end{tabular}

\subsubsection{Self-efficacy Scale for Advanced Cancer (SEAC)}

The SEAC is an 18-item scale comprising the following three subscales: Symptom Coping Self-efficacy (SCE), Activities of Daily Living Self-efficacy (ADE), and Affect Regulation Self-efficacy (ARE). Each subscale includes six items on an 11-point response scale ranging from zero $=$ not at all confident to $10=$ totally confident. The final subscale scores are calculated by summing the scores of each subscale.

\subsubsection{Oral Health-related Self-Efficacy Scale for Patients with Cancer (OSEC)}

The OSEC is a 17-item scale comprising the following five subscales: Oral Function Self-efficacy (OFE) (four items), Dental Visits Self-efficacy (DVE) (three items), Adverse Effects Self-efficacy (AEE) (four items), Symptom Coping Self-efficacy (SCE) (three items), and Brushing Habits Self-efficacy (BHE) (three items). Responses are made on a four-point Likert scale ranging from $1=$ not at all confident to $4=$ totally confident. The scores on individual items within subscales are summed to obtain total subscale scores [24].

\subsection{Statistical Analysis}

There is no missing data and all statistical analyses were performed using SPSS (ver. 26; SPSS Japan Inc., Tokyo Japan). We calculated two-tailed p-values in all the analyses. The alpha level of significance was set at 0.05 . The participants' characteristics were analyzed using descriptive statistics.

The grade of FOIS was categorized as Level 1 to 6 (Low FOIS) or Level 7 (High FOIS) based on the presence or absence of restrictions. In the inferential analysis, the Chi-squared test was used to compare proportions, while the Mann-Whitney $U$ test was used to examine the non-parametric quantitative determinations of two groups. The correlation of each variable with FOIS grade was tested by a stepwise multivariate logistic regression analysis. 
Additionally, for subgroup analysis, the FOIS grade was categorized as Level 1 to 3 (poor FOIS: tube feeding), Level 4 and 5 (moderate FOIS: total oral diet requiring special preparation) or Level 6 and 7 (good FOIS: total oral diet without special preparation). For verifying the stepwise increase or decrease in correlations between the FOIS and SEAC or OSEC's different subscales, the Jonckheere-Terpstra test was used as a trend test.

\section{Results}

\subsection{Participants' characteristics}

Table 2 presents the characteristics of the participants $(n=203)$. The median age was 71 years (male: $63.5 \%$, female: $36.5 \%$ ). The median BMI was $21.7 \mathrm{~kg} / \mathrm{m}^{2}$. The median number of days of alcohol consumption per week was 0 (range: $0-7$ ) days and the Brinkman Index was 0 (range: $0-4480$ ). The median number of co-residents was $2(0-7)$. About 72 (35.5\%) and 131 (64.5\%) patients were employed and unemployed, respectively. 
Table 2

Participants' characteristics $(n=203)$

\begin{tabular}{|c|c|c|}
\hline Variable & Percentage (n) & Median (range) \\
\hline Age (year) & & $71(34-93)$ \\
\hline \multicolumn{3}{|l|}{ Gender } \\
\hline Male & $63.5(129)$ & \\
\hline Female & $36.5(74)$ & \\
\hline Body Mass Index $\left(\mathrm{kg} / \mathrm{m}^{2}\right)$ & & $21.7(19.7-38.7)$ \\
\hline Alcohol consumption per week (day) & & $0(0-7)$ \\
\hline Brinkman Index & & $0(0-4480)$ \\
\hline Number of co-residents & & $2(0-7)$ \\
\hline \multicolumn{3}{|l|}{ Employed } \\
\hline Yes & $35.5(72)$ & \\
\hline No & $64.5(131)$ & \\
\hline \multicolumn{3}{|l|}{ Primary tumor site } \\
\hline Stomach & $13.8(28)$ & \\
\hline Colorectal & $12.3(25)$ & \\
\hline Liver & $5.4(11)$ & \\
\hline Lung & $32.0(65)$ & \\
\hline Prostate & $10.3(21)$ & \\
\hline Breast & $8.4(17)$ & \\
\hline Head/neck & $17.7(36)$ & \\
\hline \multicolumn{3}{|l|}{ Cancer stage } \\
\hline I & $38.4(78)$ & \\
\hline II & $19.2(39)$ & \\
\hline III & $20.7(42)$ & \\
\hline IV & $21.7(44)$ & \\
\hline \multicolumn{3}{|l|}{ Treatment type } \\
\hline Surgery & $59.6(121)$ & \\
\hline
\end{tabular}




\begin{tabular}{|c|c|c|}
\hline Variable & Percentage (n) & Median (range) \\
\hline Radiotherapy & $2.5(5)$ & \\
\hline Chemotherapy & $8.4(17)$ & \\
\hline Surgery and radiotherapy & $3.0(6)$ & \\
\hline Surgery and chemotherapy & $14.8(30)$ & \\
\hline Chemotherapy and radiotherapy & $4.9(10)$ & \\
\hline Surgery, chemotherapy, and radiotherapy & $6.9(14)$ & \\
\hline Number of months since last treatment & & $0(0-297)$ \\
\hline \multicolumn{3}{|c|}{ Eastern Cooperative Oncology Group Performance Status } \\
\hline 0 & $59.6(121)$ & \\
\hline 1 & $23.2(47)$ & \\
\hline 2 & $5.9(12)$ & \\
\hline 3 & $10.8(22)$ & \\
\hline 4 & $0.5(1)$ & \\
\hline Number of teeth & & $22(0-32)$ \\
\hline \multicolumn{3}{|l|}{ Dentures } \\
\hline \multicolumn{3}{|l|}{ Upper } \\
\hline None & $63.5(129)$ & \\
\hline Partial & $20.2(41)$ & \\
\hline Full & $16.3(33)$ & \\
\hline \multicolumn{3}{|l|}{ Lower } \\
\hline None & $65.5(133)$ & \\
\hline Partial & $18.7(38)$ & \\
\hline Full & $15.8(32)$ & \\
\hline \multicolumn{3}{|l|}{ Brushing times per day } \\
\hline 0 & $5.9(12)$ & \\
\hline 1 & $23.6(48)$ & \\
\hline 2 & $34.5(70)$ & \\
\hline 3 or more & $36.0(73)$ & \\
\hline
\end{tabular}




\begin{tabular}{|c|c|c|}
\hline Variable & Percentage (n) & Median (range) \\
\hline \multicolumn{3}{|l|}{ Family dentist } \\
\hline Yes & $69.5(141)$ & \\
\hline No & $30.5(62)$ & \\
\hline \multicolumn{3}{|l|}{ Dental visit(s)in the past year } \\
\hline Yes & $41.1(84)$ & \\
\hline No & $58.6(119)$ & \\
\hline \multicolumn{3}{|l|}{ Functional Oral Intake Scale } \\
\hline 1 & $3.4(7)$ & \\
\hline 2 & $0(0)$ & \\
\hline 3 & $0.5(1)$ & \\
\hline 4 & $3.4(7)$ & \\
\hline 5 & $12.8(26)$ & \\
\hline 6 & $23.2(47)$ & \\
\hline 7 & $56.7(115)$ & \\
\hline \multicolumn{3}{|l|}{$\begin{array}{l}\text { Functional Oral Intake Scale (FOIS) } \\
\text { Category } 1\end{array}$} \\
\hline High FOIS & 43.3(88) & \\
\hline Low FOIS & $56.7(115)$ & \\
\hline \multicolumn{3}{|l|}{ Category 2} \\
\hline Good FOIS & $79.8(162)$ & \\
\hline Moderate FOIS & $35(17.2)$ & \\
\hline Poor FOIS & $3(6)$ & \\
\hline \multicolumn{3}{|l|}{ Self-efficacy Scale for Advanced Cancer } \\
\hline Affect regulation self-efficacy & & $58.3(8-100)$ \\
\hline Symptom coping self-efficacy & & $51.7(2-100)$ \\
\hline Activities of daily living self-efficacy & & $63.3(2-100)$ \\
\hline Total Score & & $1050(70-1800)$ \\
\hline
\end{tabular}




\begin{tabular}{|c|c|c|}
\hline Variable & Percentage (n) & Median (range) \\
\hline Brushing Habits Self-efficacy & & $8(3-12)$ \\
\hline Oral Function Self-efficacy & & $11(5-16)$ \\
\hline Dental visit Self-efficacy & & $8(3-12)$ \\
\hline Symptom Coping Self-efficacy & & $9(3-12)$ \\
\hline Adverse Effects Self-efficacy & & $10(4-16)$ \\
\hline Total Score & & $45(30-68)$ \\
\hline
\end{tabular}

Stomach, colorectal, liver, lung, prostate, breast, and head/neck were the primary tumor site in 28 (13.8\%), 25 (12.3), 11 (5.4\%), 65 (32\%), 21 (10.3\%), 17 (8.4\%), and 36 (17.7\%) patients, respectively. Concerning the cancer stage, $78(38.4 \%), 39(19.2 \%), 42(20.7 \%)$, and $44(21.7 \%)$ patients were at stage I, II, III, and IV, respectively. The treatment type included surgery $(n=121 ; 59.6 \%)$; radiotherapy $(n=5 ; 2.5 \%)$; chemotherapy $(n=17 ; 8.4 \%)$; surgery and radiotherapy $(n=6 ; 3 \%)$; surgery and chemotherapy $(n=30$; $14.8 \%)$; chemotherapy and radiotherapy $(n=10 ; 4.9 \%)$; and surgery, chemotherapy, and radiotherapy $(n=$ $14 ; 6.9 \%$ ). The median number of months in the past year treatment was 0 (range: $0-297$ ). Eastern Cooperative Oncology Group Performance Status was Grade 0, 1, 2, 3, and 4 for 121 (59.6\%), 47 (23.2\%), $12(5.9 \%), 22(10.8 \%)$, and 1 (0.5\%) patient, respectively.

The median number of teeth was 22 (range: 0-32). Regarding upper dentures, 129 (63.5\%), 41 (20.2\%), and $33(16.3 \%)$ patients had no, partial, and full dentures, respectively. Regarding lower dentures, 133 (65.5\%), 38 (18.7\%), and 32 (15.8\%) patients had no, partial, and full dentures, respectively. About 12 (5.9\%), 48 (23.6\%), 70 (34.5\%), and 73 (36\%) patients brushed their teeth 0, 1, 2, and 3 or more times per day, respectively. About $141(69.5 \%)$ patients had a family dentist and $84(41.4 \%)$ patients had made a dental visit(s) in the past year. Regarding FOIS level, 7 (13.4\%), 0 (0\%), 1 (0.5\%), 7 (3.4\%), 26 (12.8\%), 47 (23.2\%), and 115 (56.7\%) patients had scores at Level 1, 2, 3, 4, 5, 6, and 7, respectively. In FOIS Category 1, $88(43.3 \%)$ and $115(56.7 \%)$ patients were in high and low FOIS, respectively. In FOIS Category 2, 162 (79.8\%), 35 (17.2\%), and $3(6 \%)$ patients were in good, moderate, and poor FOIS, respectively. The median SEAC total score was 1050, while that for the ARE, SCE, and ADE subscales was 58.3, 51.7, and 63.3, respectively. The median OSEC total score was 45 , and that for the BHE, OFE, DVE, SCE, and AEE subscales was $8,11,8,9$, and 10 , respectively.

\subsection{Comparison of high and low FOIS groups}

Table 3 summarizes the variables compared between the high and low FOIS groups. Statistically significant differences were found in age, gender, BMI, Brinkman index, primary tumor site (lung, breast, and head/neck), cancer stage, treatment type (surgery; surgery and chemotherapy; surgery, chemotherapy, and radiotherapy), performance status, number of teeth, brushing times, family dentist, dental visit(s), 
SEAC (ARE, ADE, and total score), and OEAC (OFE and total score). No significant differences were found in other variables. 
Table 3

Comparison of the high versus low Functional Oral Intake Scale analysis of each item

\begin{tabular}{|c|c|c|c|}
\hline \multirow[t]{2}{*}{ Variable } & \multicolumn{2}{|c|}{ Percentage (n) or Median (range) } & \multirow{2}{*}{$\begin{array}{l}\mathrm{p}- \\
\text { value }\end{array}$} \\
\hline & $\begin{array}{l}\text { High FOIS }(n= \\
88)\end{array}$ & $\begin{array}{l}\text { Low FOIS }(n= \\
115)\end{array}$ & \\
\hline Age (year) & $72(34-93)$ & $69(36-91)$ & $\begin{array}{l}< \\
0.01 *\end{array}$ \\
\hline \multicolumn{4}{|l|}{ Gender } \\
\hline Male & $66(75)$ & $63(54.8)$ & \multirow{2}{*}{$<.01 *$} \\
\hline Female & $22(25)$ & $52(45.2)$ & \\
\hline Body Mass Index $\left(\mathrm{kg} / \mathrm{m}^{2}\right)$ & $\begin{array}{l}21.3(15.2- \\
28.8)\end{array}$ & $22.4(19.338 .7)$ & $0.04^{*}$ \\
\hline Alcohol consumption per week (day) & $0(0-7)$ & $0(0-7)$ & 0.45 \\
\hline Brinkman Index & $160(0-4160)$ & $0(0-4480)$ & $\begin{array}{l}< \\
0.01 *\end{array}$ \\
\hline Number of co-residents & $2(0-7)$ & $1(0-7)$ & 0.08 \\
\hline \multicolumn{4}{|l|}{ Employed } \\
\hline Yes & $30(34.1)$ & $42(36.5)$ & \multirow[t]{2}{*}{0.77} \\
\hline No & $58(65.9)$ & $73(63.5)$ & \\
\hline \multicolumn{4}{|l|}{ Primary tumor site } \\
\hline Stomach & $18(20.5)$ & $10(8.7)$ & 0.02 \\
\hline Colorectal & $13(14.8)$ & $12(10.4)$ & 0.35 \\
\hline Liver & $4(4.5)$ & $7(6.1)$ & 0.63 \\
\hline Lung & $18(20.5)$ & $47(40.9)$ & $<.01$ * \\
\hline Prostate & $9(10.2)$ & $12(10.4)$ & 0.96 \\
\hline Breast & $1(1.1)$ & $16(13.9)$ & $\begin{array}{l}<.01 * \\
0.01\end{array}$ \\
\hline Head/neck & $25(28.4)$ & $11(9.6)$ & $<.01 *$ \\
\hline \multicolumn{4}{|l|}{ Cancer stage } \\
\hline I & $20(22.7)$ & $58(50.4)$ & $<.01 *$ \\
\hline
\end{tabular}




\begin{tabular}{|c|c|c|c|}
\hline \multirow[t]{2}{*}{ Variable } & \multicolumn{2}{|c|}{ Percentage (n) or Median (range) } & \multirow{2}{*}{$\begin{array}{l}\text { p- } \\
\text { value }\end{array}$} \\
\hline & $\begin{array}{l}\text { High FOIS }(n= \\
88)\end{array}$ & $\begin{array}{l}\text { Low FOIS }(n= \\
115)\end{array}$ & \\
\hline II & $16(18.2)$ & $23(20)$ & \\
\hline III & $21(23.9)$ & $21(18.3)$ & \\
\hline IV & $31(35.2)$ & $13(11.3)$ & \\
\hline \multicolumn{4}{|l|}{ Treatment type } \\
\hline Surgery & $38(43.2)$ & $83(72.2)$ & $\dot{0.01 *}$ \\
\hline Radiotherapy & $1(1.1)$ & $4(3.5)$ & 0.29 \\
\hline Chemotherapy & $10(11.4)$ & $7(6.1)$ & 0.18 \\
\hline Surgery and radiotherapy & $4(4.5)$ & $2(1.7)$ & 0.24 \\
\hline Surgery and chemotherapy & $18(20.5)$ & $12(10.4)$ & $0.05^{\star}$ \\
\hline Chemotherapy and radiotherapy & $6(6.8)$ & $4(3.5)$ & 0.28 \\
\hline Surgery, chemotherapy, and radiotherapy & $11(12.5)$ & $3(2.6)$ & $\begin{array}{l}< \\
0.01 *\end{array}$ \\
\hline Number of months since last treatment & $1(0-297)$ & $0(0-216)$ & 0.06 \\
\hline \multicolumn{4}{|c|}{$\begin{array}{l}\text { Eastern Cooperative Oncology Group Performance } \\
\text { Status }\end{array}$} \\
\hline 0 & $29(33)$ & $92(80)$ & \multirow{5}{*}{$<.01$} \\
\hline 1 & $31(35.2)$ & $16(13.9)$ & \\
\hline 2 & $9(10.2)$ & $3(2.6)$ & \\
\hline 3 & $18(20.5)$ & $4(3.5)$ & \\
\hline 4 & $1(1.1)$ & $0(0)$ & \\
\hline Number of teeth & $15(0-32)$ & $25(0-32)$ & $\dot{0.01 *}$ \\
\hline \multicolumn{4}{|l|}{ Brushing times per day } \\
\hline 0 & $10(11.4)$ & $2(1.7)$ & \multirow{4}{*}{$<.01 *$} \\
\hline 1 & $27(30.7)$ & $21(18.3)$ & \\
\hline 2 & $25(28.4)$ & $45(39.1)$ & \\
\hline 3 or more & $26(29.5)$ & 47 (40.9) & \\
\hline
\end{tabular}




\begin{tabular}{|c|c|c|c|}
\hline \multirow[t]{2}{*}{ Variable } & \multicolumn{2}{|c|}{ Percentage (n) or Median (range) } & \multirow{2}{*}{$\begin{array}{l}\mathrm{p}- \\
\text { value }\end{array}$} \\
\hline & $\begin{array}{l}\text { High FOIS }(n= \\
88)\end{array}$ & $\begin{array}{l}\text { Low FOIS }(n= \\
115)\end{array}$ & \\
\hline \multicolumn{4}{|l|}{ Family dentist } \\
\hline Yes & $46(52.3)$ & $95(82.6)$ & \multirow{2}{*}{$\begin{array}{l}<.01 * \\
0.0\end{array}$} \\
\hline No & $42(47.7)$ & $20(17.4)$ & \\
\hline \multicolumn{4}{|l|}{ Dental visit(s) in the past year } \\
\hline Yes & $25(28.4)$ & $59(51.3)$ & \multirow{2}{*}{ <.01* } \\
\hline No & $63(71.6)$ & $56(48.7)$ & \\
\hline \multicolumn{4}{|c|}{ Self-efficacy Scale for Advanced Cancer } \\
\hline Affect regulation self-efficacy & $50.8(8-97)$ & $61.7(13-100)$ & $<.01 *$ \\
\hline Symptom coping self-efficacy & $50(2-90)$ & $53.3(7-100)$ & 0.07 \\
\hline Activities of daily living self-efficacy & $52.5(2-93)$ & $68.3(17-100)$ & $\begin{array}{l}<.01 * \\
0.01\end{array}$ \\
\hline Total Score & $915(70-1640)$ & $\begin{array}{l}1100(280- \\
1800)\end{array}$ & $<.01 *$ \\
\hline \multicolumn{4}{|c|}{$\begin{array}{l}\text { Oral Health-related Self-Efficacy Scale for Patients } \\
\text { with Cancer }\end{array}$} \\
\hline Brushing Habits Self-efficacy & $8(3-12)$ & $8(3-12)$ & 0.31 \\
\hline Oral Function Self-efficacy & $10(5-16)$ & $11(5-16)$ & $<.01 *$ \\
\hline Dental visit Self-efficacy & $8(3-12)$ & $9(3-12)$ & 0.31 \\
\hline Symptom Coping Self-efficacy & $9(6-12)$ & $9(3-12)$ & 0.96 \\
\hline Adverse Effects Self-efficacy & $10(4-16)$ & $10(4-16)$ & 0.53 \\
\hline Total Score & $44(33-64)$ & $46(30-68)$ & $0.05^{\star}$ \\
\hline
\end{tabular}

\subsection{Multivariate analysis}

The multivariate analysis showed a statistically significant correlation between the low FOIS score category and number of co-residents (odds ratio $0.70,95 \%$ confidence interval [Cl] 0.53-0.92), stomach cancer (odds ratio 5.05, 95\% [Cl] 1.01-25.33), colorectal cancer (odds ratio 42.74, 95\% [Cl] 5.71-319.92), liver cancer (odds ratio 46.95, 95\% [Cl] 3.77-584.4), lung cancer (odds ratio 37.13, 95\% [Cl] 7.62-181.1), prostate cancer (odds ratio 11.2, 95\% [CI] 1.69-74.29), breast cancer (odds ratio 334.15, 95\% [CI] 6.21- 
17969.17), cancer stage (odds ratio 0.60,95\% [Cl] 0.38-0.94), Eastern Cooperative Oncology Group Performance Status (odds ratio $0.52,95 \%$ [CI] 0.31-0.90), number of teeth (odds ratio 1.16, 95\% [Cl] 1.09-1.23), family dentist (odds ratio 6.55, 95\% [Cl] 2.07-20.75), ADE score on the SEAC (odds ratio 1.04, 95\% [CI] 1.00-1.07), and SCE score on the SEAC (odds ratio 0.61, 95\% [CI] 0.42-0.88) (Table 4). 
Table 4

Correlation between related factor(s) and High or Low Functional Oral Intake Scale by multivariate analysis

\begin{tabular}{|c|c|c|c|c|c|c|}
\hline \multirow[t]{2}{*}{ Variable } & \multirow{2}{*}{$\begin{array}{l}\text { Regression } \\
\text { coefficient }\end{array}$} & \multirow[t]{2}{*}{ Wald } & \multirow{2}{*}{$\begin{array}{l}\text { Significance } \\
\text { probability }\end{array}$} & \multirow{2}{*}{$\begin{array}{l}\text { Odds ratio } \\
\text { ( } 95 \% \\
\text { confidence } \\
\text { interval) }\end{array}$} & \multicolumn{2}{|c|}{$\operatorname{EXP}(B)$} \\
\hline & & & & & $\begin{array}{l}\text { Lower } \\
\text { limit }\end{array}$ & $\begin{array}{l}\text { Upper } \\
\text { limit }\end{array}$ \\
\hline $\begin{array}{l}\text { Number of co- } \\
\text { residents }\end{array}$ & -0.36 & 6.54 & $<0.01^{*}$ & 0.70 & 0.53 & 0.92 \\
\hline Employed & -0.94 & 2.79 & 0.10 & 0.39 & 0.13 & 1.18 \\
\hline Stomach cancer & 1.62 & 3.87 & $0.05^{\star}$ & 5.05 & 1.01 & 25.33 \\
\hline Colorectal cancer & 3.76 & 13.37 & $<0.01^{\star}$ & 42.74 & 5.71 & 319.92 \\
\hline Liver cancer & 3.85 & 8.95 & $<0.01^{\star}$ & 46.95 & 3.77 & 584.4 \\
\hline Lung cancer & 3.62 & 20.0 & $<0.01^{*}$ & 37.13 & 7.62 & 181.1 \\
\hline Prostate cancer & 2.42 & 6.27 & $<0.01^{\star}$ & 11.2 & 1.69 & 74.29 \\
\hline Breast cancer & 5.81 & 8.17 & $<0.01^{*}$ & 334.15 & 6.21 & 17969.17 \\
\hline Cancer stage & -0.52 & 4.98 & $0.03^{*}$ & 0.60 & 0.38 & 0.94 \\
\hline Radiotherapy & 3.48 & 2.38 & 0.12 & 32.38 & 0.39 & 2674.8 \\
\hline $\begin{array}{l}\text { Surgery and } \\
\text { chemotherapy }\end{array}$ & -1.19 & 2.82 & 0.09 & 0.30 & 0.08 & 1.22 \\
\hline $\begin{array}{l}\text { Eastern Cooperative } \\
\text { Oncology Group } \\
\text { Performance Status }\end{array}$ & -0.65 & 5.56 & $0.02 *$ & 0.52 & 0.31 & 0.90 \\
\hline Number of teeth & 0.15 & 25.2 & $<0.01^{*}$ & 1.16 & 1.09 & 1.23 \\
\hline Family dentist & 1.88 & 10.21 & $<0.01^{*}$ & 6.55 & 2.07 & 20.75 \\
\hline $\begin{array}{l}\text { Activities of daily } \\
\text { living self-efficacy }\end{array}$ & 0.04 & 4.42 & $0.04 *$ & 1.04 & 1.00 & 1.07 \\
\hline $\begin{array}{l}\text { Symptom Coping Self- } \\
\text { efficacy }\end{array}$ & -0.49 & 7.04 & $<0.01^{*}$ & 0.61 & 0.42 & 0.88 \\
\hline Constant & 2.66 & 0.88 & 0.35 & 14.354 & & \\
\hline
\end{tabular}

3.4. Sub group analysis (trend test) 
The Jonckheere-Terpstra test revealed a stepwise increase in scores on each subscale of the SEAC (ARE, SCE, ADE, and total score) and OSEC (OFE and total score) with the progression of the FOIS category (Fig. 1-2). Specifically, as the FOIS category progressed, the SEAC and OSEC scores tended to increase.

\section{Discussion}

\subsection{Generalizability from the demographic data}

This study represents several factors of self-efficacy that affect the swallowing function. The prevalence of malnutrition in Europe and North America is 1-15\% among non-institutionalized older adults, 25-60\% among older adults in geriatric care facilities, and 35-65\% among older adults in hospitals, and our sample presented the same level of prevalence (43.3\%) [27]. Additionally, Frowen et al. reported similar characteristics (male: 49\%; mean age: 59 years; tumor type: 20.5\% hematology, 18.4\% breast, 11.3\% head and neck, 10\% Gynecology, 8.8\% upper gastrointestinal, 8.8\% colorectal, 8.4\% skin/melanoma, 4.6\% bone soft tissue, 3.8\% lung, 5.4\% other; patient setting: $21.3 \%$ inpatient, $56.1 \%$ chemotherapy, $22.6 \%$ radiotherapy) and prevalence of patient-reported dysphagia (54\%) [7]. However, most patients in the present sample had solid cancer and the most common treatment type was surgery, which may lead to a low prevalence of dysphagia as compared to that observed in the previous study. With reference to oral health status, previous studies reported that the prevalence of denture use was $15.9 \%$ (57.4\% in our study), and that of dental visit(s) in the last 12 months was $52.1 \%(41.1 \%$ in our study) $[28,29]$. The number of teeth reported in our study was lesser than that reported in other studies, which may affect OSEC and FOIS scores. Globally, we may be the first to report the FOIS score of general cancer patients; however, those with head and neck cancer tended to exhibit poor FOIS scores, which was consistent with the findings of previous studies $[30,31]$. The study by Hirai et al. on self-efficacy (SEAC) in patients with advanced cancer showed similar results (ARE: 57.7-84.8, SCE: 53.6-61.2, ADE: 64.8-72.9). Thus, the generalizability of the present study was limited to patients with early-stage cancer undergoing initial treatment.

\subsection{Comparison of the High and Low FOIS groups by swallowing function}

The factors influencing swallowing functions were age, sex, BMI > 30, smoking status, alcohol use, cognitive factors (depression, anxiety, and psychological distress), eating habits (loss of appetite, mouth pain, complaints about the taste of the food, intake of dietary supplements, and ability to eat independently), medical factors (vision or hearing problems, constipation, heart failure, hip fracture, stroke, dementia, Parkinson's disease, weight loss, frailty and number of medications taken in the past week, physical limitations, toxic habits, and cancer), social factors (highest level of education, income satisfaction, type of housing, number of cohabitants, and perceived satisfaction with social support) and dental status [32-37]. The factors reported in the present study have also been reported by previous studies, thus, our results on comparisons between high and low FOIS groups were not contradicted. Notably, there were significant differences between the high and low FOIS groups' scores on the SEAC (ARE, ADE, and total score) and OSEC (OFE and total score). These may be new findings on self-efficacyrelated factors that influence swallowing functions. Self-efficacy expectations are positively and significantly associated with the initiation and maintenance of healthy behaviors [38, 39]. Thus, self- 
efficacy may determine the ability of cancer patients to eat or select appropriate food. Moreover, these abilities may influence the probability of weight loss, appetite loss, and recurrence of cancer [40]. The multivariate analysis conducted in the present study revealed factors associated with the FOIS category (number of co-residents, cancer type and stage, performance status, number of teeth, family dentist, and ADE and SCE scores on the SEAC). However, contrary to our expectations, OSEC scores were not associated with the swallowing function. According to Bandura, the development of self-efficacy related to an activity is based upon past successful experiences with that specific behavior [18]. Therefore, patients who experience these swallowing disorders after the deterioration of their ability to perform activities of daily living may have difficulty in drawing from past successful experiences, thus reducing their confidence in performing the swallowing function. In other words, there may be an underlying interaction between swallowing function and OSEC scores.

\subsection{Trends in FOIS scores and self-efficacy}

In the sub-group analysis, all subscales of the SEAC, and the OFE and total score on the OSEC showed a stepwise increase in FOIS score. Thus, self-efficacy showed a stepwise correlation with the FOIS score. More attention should be paid to the provision of care and coaching focused on defusing negative emotional experiences in each stage of dysphagia and self-efficacy. Our previous report showed the stepwise correlation between the HRQoL and FOIS score [31]. Therefore, such interventions may enhance the patient's confidence in their swallowing abilities.

\subsection{Intervention for cancer patients suffering from swallowing dysfunction}

Oral care containing rehabilitation of dysphagia and oral function, whether self-performed or performed by dentists and dental hygienists, is fundamental to the prevention of some adverse events (postoperative pneumonia, chemoradiotherapy-induced oral mucositis, taste disturbance, infection of the oral cavity, and swallowing disorder)[41]. Dysphagia is widely recognized as a common and debilitating side-effect of head and neck cancer (HNC) and its treatment; however, minimal attention has been given to dysphagia in patients with other types of cancer [3]. A review highlighted several methods of rehabilitation for dysphagia in head and neck cancer, and their effectiveness was evidenced by a randomized control trial [42]. However, most of the rehabilitation efforts for head and neck cancer patients with dysphagia focus on the pathophysiology of dysphagia, including objective assessment (videoendoscopic evaluation of swallowing, videofluoroscopic examination of swallowing, dysphagia severity scale, and the FOIS) [43]. However, a psychosocial approach should be emphasized for cancer patients with dysphagia. The food judged by the medical staff as edible is not the same as what the patients can or want to eat. In a prospective cohort study of 100 patients with either transient ischemic attack or ischemic stroke, Brouwer et al. found that baseline self-efficacy, as determined by patients' responses on questionnaires, was the strongest predictor of his/her intention to adopt a healthy diet (95\% $\mathrm{Cl}, 0.23-0.75)[22]$. Thus, based on the aforementioned studies, it may be beneficial for hospitals' neurosurgery and neurology departments to coordinate long-term stroke coaching programs and assess patients' behavioral patterns to increase patients' adherence to healthy lifestyles. On the other hand, in patients with head and neck cancer, Roganie et al. reviewed only 15 (8 randomized) behavior change technique (BCT) reports, and they reported that BCTs used more frequently in effective interventions were: practical social support; behavioral practice; self-monitoring of behavior; and credible source, for example, 
a skilled clinician delivering the intervention. As a result, swallowing interventions feature multiple components that may potentially impact outcomes [44]. These BCTs may improve the discrepancy of objective and subjective dysphagia.

This study had some limitations. First, our study design was cross-sectional; therefore we could not determine the causal relationship between dysphagia and self-efficacy. Particularly, we observed the stepwise tendency between self-efficacy and FOIS; however, it was evaluated only at a specific instance. Thus, a future study should verify the stepwise relationship between self-efficacy and FOIS using a longitudinal design. Second, the participants who visited the oral care center had good oral health-related knowledge and attitudes; therefore, it is likely that they represented a higher oral health related-selfefficacy. Therefore, selection bias might exist. Although we consider that observational studies cannot avoid such selection bias, we believe that our findings provide important suggestions for randomized controlled trials in the future, which would reveal the actual impact of self-efficacy.

\section{Conclusion}

Generally, self-efficacy played an important role in dysphagia and may affect the severity of dysphagia.

\section{Abbreviations}

FOIS: functional oral intake scale; SEAC: self-efficacy scale for advanced cancer; SCE: symptom coping self-efficacy; ADE: activities of daily living self-efficacy; ARE: affect regulation self-efficacy; OSEC: oral health-related self-efficacy scale for patients with cancer; OFE: oral function self-efficacy; DVE: dental visits self-efficacy; AEE: adverse effects self-efficacy; SCE: symptom coping self-efficacy; BHE: brushing habits self-efficacy; GSES: general self-efficacy scale; HRQoL: health-related quality of life; BMI: body mass index; $\mathrm{Cl}$ : confidence interval; HNC: head and neck cancer; $\mathrm{BCT}$ : behavior change technique

\section{Declarations}

\section{Funding}

This research was funded by JSPS KAKENHI Grant Number17K17379.

Availability of data and materials

The datasets used and analyzed in this study are unavailable.

\section{Ethics Approval and Consent to Participate}

All study participants provided informed consent, and the appropriate ethics review board (the medical ethics committee of Shimane University Faculty of Medicine approved this study, approval number: 3243) approved the study design.

Consent for publication 
Not applicable.

\section{Competing interests}

The authors declare that they have no competing interests in this study. No

financial or non-financial interests influenced the interpretation of the data

or presentation of the information.

\section{Author Contributions}

Conceptualization, Y.M.; data curation, Y.M.; formal analysis, Y.M.; funding acquisition, Y.M.; investigation, Y.M.; methodology, Y.M.; project administration, T.K. and M.K.; supervision, T.K. and M.K.; validation, T.K. and M.K.; visualization, Y.M., T.K., and M.K.; writing-original draft, Y.M.; writing-review and editing, T.K. and M.K. All authors read and approved the final manuscript.

\section{Acknowledgments}

We are grateful to the respondents for their voluntary participation. We extend our appreciation to all staff members of the Oral Care Center and the Department of Oral and Maxillofacial Surgery, Faculty of Medicine, Shimane University, for their assistance and support.

\section{References}

1. Hui D, Dev R, Bruera E. The last days of life: symptom burden and impact on nutrition and hydration in cancer patients. Curr Opin Support Palliat Care. 2015;9(4):346-54.

2. Torres-Vigil I, Cohen MZ, de la Rosa A, Cardenas-Turanzas M, Burbach BE, Tarleton KW, et al. Food or medicine: ethnic variations in perceptions of advanced cancer patients and their caregivers regarding artificial hydration during the last weeks of life. BMJ Support Palliat Care. 2012:2(3):276-9.

3. Frowen J. Dysphagia in patients with non-head and neck cancer. Curr Opin Otolaryngol Head Neck Surg. 2019;27(3):162-7.

4. Halpern AL, McCarter MD. Palliative management of gastric and esophageal cancer. Surg Clin North Am. 2019;99(3):555-69.

5. Koldenhof JJ, Langenberg MHG, Witteveen PO, Teunissen S. Patient-reported symptoms and stepwise symptom management in patients on epidermal growth factor inhibitors: A retrospective, descriptive cohort study. Eur J Cancer Care (Engl). 2018;27(2):e12800.

6. Abbas MN, Ayoola A, Padman S, Kumar R, Leung J, Ullah S, et al. Survival and late toxicities following concurrent chemo-radiotherapy for locally advanced stage III non-small cell lung cancer: findings of a 10-year Australian single centre experience with long term clinical follow up. J Thorac Dis. 2019;11(10):4241-8. 
7. Frowen J, Hughes R, Skeat J. The prevalence of patient-reported dysphagia and oral complications in cancer patients. Support Care Cancer. 2020;28(3):1141-50.

8. Kristensen MB, Isenring E, Brown B. Nutrition and swallowing therapy strategies for patients with head and neck cancer. Nutrition. 2020;69:110548.

9. Zuercher P, Moret CS, Dziewas R, Schefold JC. Dysphagia in the intensive care unit: epidemiology, mechanisms, and clinical management. Crit Care. 2019;23(1):103.

10. Timmerman AA, Speyer R, Heijnen BJ, Klijn-Zwijnenberg IR. Psychometric characteristics of healthrelated quality-of-life questionnaires in oropharyngeal dysphagia. Dysphagia. 2014;29(2):183-98.

11. Youssof S, Romero-Clark C, Warner T, Plowman E. Dysphagia-related quality of life in oculopharyngeal muscular dystrophy: Psychometric properties of the SWAL-QOL instrument. Muscle Nerve. 2017;56(1):28-35.

12. Ekberg O, Hamdy S, Woisard V, Wuttge-Hannig A, Ortega P. Social and psychological burden of dysphagia: its impact on diagnosis and treatment. Dysphagia. 2002;17(2):139-46.

13. Gustafsson B, Tibbling L. Dysphagia, an unrecognized handicap. Dysphagia. 1991;6(4):193-9.

14. McHorney CA, Martin-Harris B, Robbins J, Rosenbek J. Clinical validity of the SWAL-QOL and SWALCARE outcome tools with respect to bolus flow measures. Dysphagia. 2006;21(3):141-8.

15. Stringer S. Managing dysphagia in palliative care. Prof Nurse. 1999;14(7):489-92.

16. Lieber AC, Hong E, Putrino D, Nistal DA, Pan JS, Kellner CP. Nutrition, energy expenditure, dysphagia, and self-efficacy in stroke rehabilitation: A review of the literature. Brain Sci. 2018;8(12).

17. Perry A, Casey E, Cotton S. Quality of life after total laryngectomy: functioning, psychological wellbeing and self-efficacy. Int J Lang Commun Disord. 2015;50(4):467-75.

18. Bandura A. Self-efficacy: toward a unifying theory of behavioral change. Psychol Rev. 1977;84(2):191-215.

19. Kakudate N, Morita M, Fukuhara S, Sugai M, Nagayama M, Isogai E, et al. Development of the outcome expectancy scale for self-care among periodontal disease patients. J Eval Clin Pract. 2011;17(6):1023-9.

20. Mullen SP, McAuley E, Satariano WA, Kealey M, Prohaska TR. Physical activity and functional limitations in older adults: the influence of self-efficacy and functional performance. J Gerontol B Psychol Sci Soc Sci. 2012;67(3):354-61.

21. Voogt CV, Kuntsche E, Kleinjan M, Engels RC. The effect of the 'What Do You Drink' web-based brief alcohol intervention on self-efficacy to better understand changes in alcohol use over time: randomized controlled trial using ecological momentary assessment. Drug Alcohol Depend. 2014;138:89-97.

22. Brouwer-Goossensen D, Genugten LV, Lingsma H, Dippel D, Koudstaal P, Hertog HD. Determinants of intention to change health-related behavior and actual change in patients with TIA or minor ischemic stroke. Patient Educ Couns. 2016;99(4):644-50. 
23. Hirai K, Suzuki Y, Tsuneto S, Ikenaga M, Hosaka T, Kashiwagi T. A structural model of the relationships among self-efficacy, psychological adjustment, and physical condition in Japanese advanced cancer patients. Psychooncology. 2002;11(3):221-9.

24. Matsuda Y, Karino M, Kanno T. Development and validation of the Oral-Health-Related Self-Efficacy Scale for Cancer Patients. J Cancer Educ. 2020, (Online ahead of print)

25. Gillham S, Endacott R. Impact of enhanced secondary prevention on health behaviour in patients following minor stroke and transient ischaemic attack: a randomized controlled trial. Clin Rehabil. 2010;24(9):822-30.

26. Kushner DS, Johnson-Greene D, Cordero MK, Thomashaw SA, Rodriguez J. Swallowing outcomes and discharge destinations in acute-stroke tube-feeding-dependent dysphagia patients treated with neuromuscular-electrical-stimulation during inpatient rehabilitation. Am J Phys Med Rehabil. 2019 (Online ahead of print).

27. Gil-Montoya JA, Ponce G, Sanchez Lara I, Barrios R, Llodra JC, Bravo M. Association of the oral health impact profile with malnutrition risk in Spanish elders. Arch Gerontol Geriatr. 2013;57(3):398402.

28. Han MA. Oral health status and behavior among cancer survivors in korea using nationwide survey. Int J Environ Res Public Health. 2017;15(1).

29. Marino R, Hopcraft M, Ghanim A, Tham R, Khew CW, Stevenson C. Oral health-related knowledge, attitudes and self-efficacy of Australian rural older adults. Gerodontology. 2016;33(4):530-8.

30. Maeda K, Wakabayashi H, Shamoto H, Akagi J. Cognitive impairment has no impact on hospitalassociated dysphagia in aspiration pneumonia patients. Geriatr Gerontol Int. 2018;18(2):233-239.

31. Matsuda Y, Kanazawa M, Komagamine Y, Yamashiro M, Akifusa S, Minakuchi S. Reliability and validity of the MD Anderson Dysphagia Inventory among japanese patients. Dysphagia. 2018;33(1):123-32.

32. Shatenstein B, Kergoat MJ, Nadon S. Weight change, nutritional risk and its determinants among cognitively intact and demented elderly Canadians. Can J Public Health. 2001;92(2):143-9.

33. Mamhidir AG, Ljunggren G, Kihlgren M, Kihlgren A, Wimo A. Underweight, weight loss and related risk factors among older adults in sheltered housing-a Swedish follow-up study. J Nutr Health Aging. 2006;10(4):255-62.

34. Roberts KC, Wolfson C, Payette H. Predictors of nutritional risk in community-dwelling seniors. Can J Public Health. 2007;98(4):331-6.

35. Jyrkka J, Enlund H, Lavikainen P, Sulkava R, Hartikainen S. Association of polypharmacy with nutritional status, functional ability and cognitive capacity over a three-year period in an elderly population. Pharmacoepidemiol Drug Saf. 2011;20(5):514-22.

36. Serra-Prat M, Palomera M, Gomez C, Sar-Shalom D, Saiz A, Montoya JG, et al. Oropharyngeal dysphagia as a risk factor for malnutrition and lower respiratory tract infection in independently living older persons: a population-based prospective study. Age Ageing. 2012;41(3):376-81. 
37. Schilp J, Wijnhoven HA, Deeg DJ, Visser M. Early determinants for the development of undernutrition in an older general population: Longitudinal Aging Study Amsterdam. Br J Nutr. 2011;106(5):708-17.

38. Vellema M, Ko MC, Frankl-Vilches $C$, Gahr M. What makes a marker a good marker?. Commentary on Balthazart $\mathrm{J}$ and Ball $\mathrm{G}$ (2014): Doublecortin is a highly valuable endogenous marker of adult neurogenesis in canaries. Brain Behav Evol 84:1-4. Brain Behav Evol. 2014;84(1):5-7.

39. Armbruster C, Gale B, Brady J, Thompson N. Perceived ownership in a community coalition. Public Health Nurs. 1999;16(1):17-22.

40. Tiwari P, Kumar L, Thulkar S, Singh G, Malik P, Seth A. Patient reported weight loss predicts recurrence rate in renal cell cancer cases after nephrectomy. Asian Pac J Cancer Prev. 2018;19(4):891-895.

41. Montero PH, Patel SG. Cancer of the oral cavity. Surg Oncol Clin N Am. 2015;24(3):491-508.

42. Pauloski BR. Rehabilitation of dysphagia following head and neck cancer. Phys Med Rehabil Clin $\mathrm{N}$ Am. 2008;19(4):889-928, x.

43. Holmes S. A service evaluation of cough reflex testing to guide dysphagia management in the postsurgical adult head and neck patient population. Curr Opin Otolaryngol Head Neck Surg. 2016;24(3):191-6.

44. Govender R, Smith $\mathrm{CH}$, Taylor SA, Barratt H, Gardner B. Swallowing interventions for the treatment of dysphagia after head and neck cancer: a systematic review of behavioural strategies used to promote patient adherence to swallowing exercises. BMC Cancer. 2017;17(1):43.

\section{Figures}



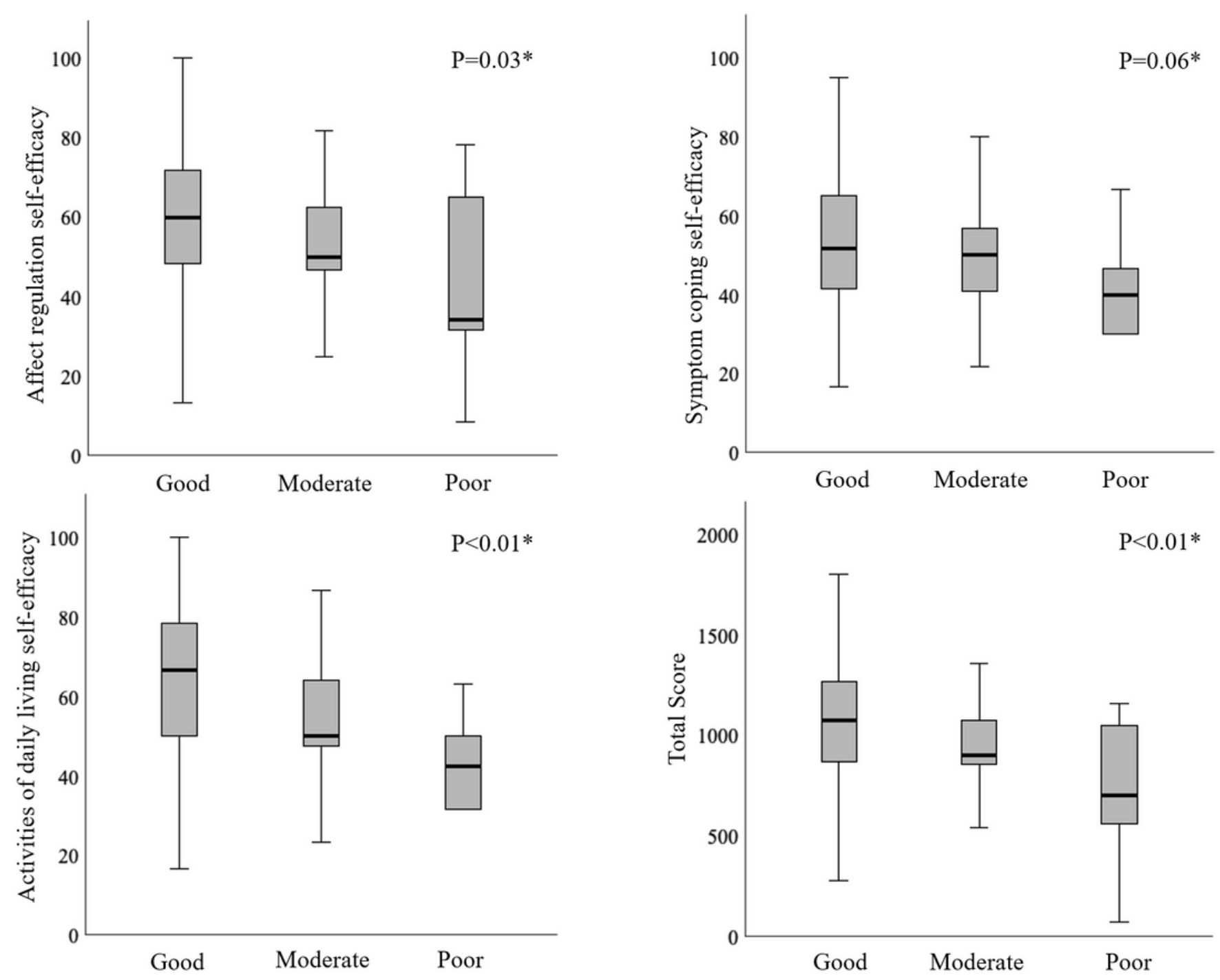

Figure 1

Stepwise correlation between the Self-efficacy Scale for Advanced Cancer and Functional Oral Intake Scale using the Jonckheere-Terpstra test 

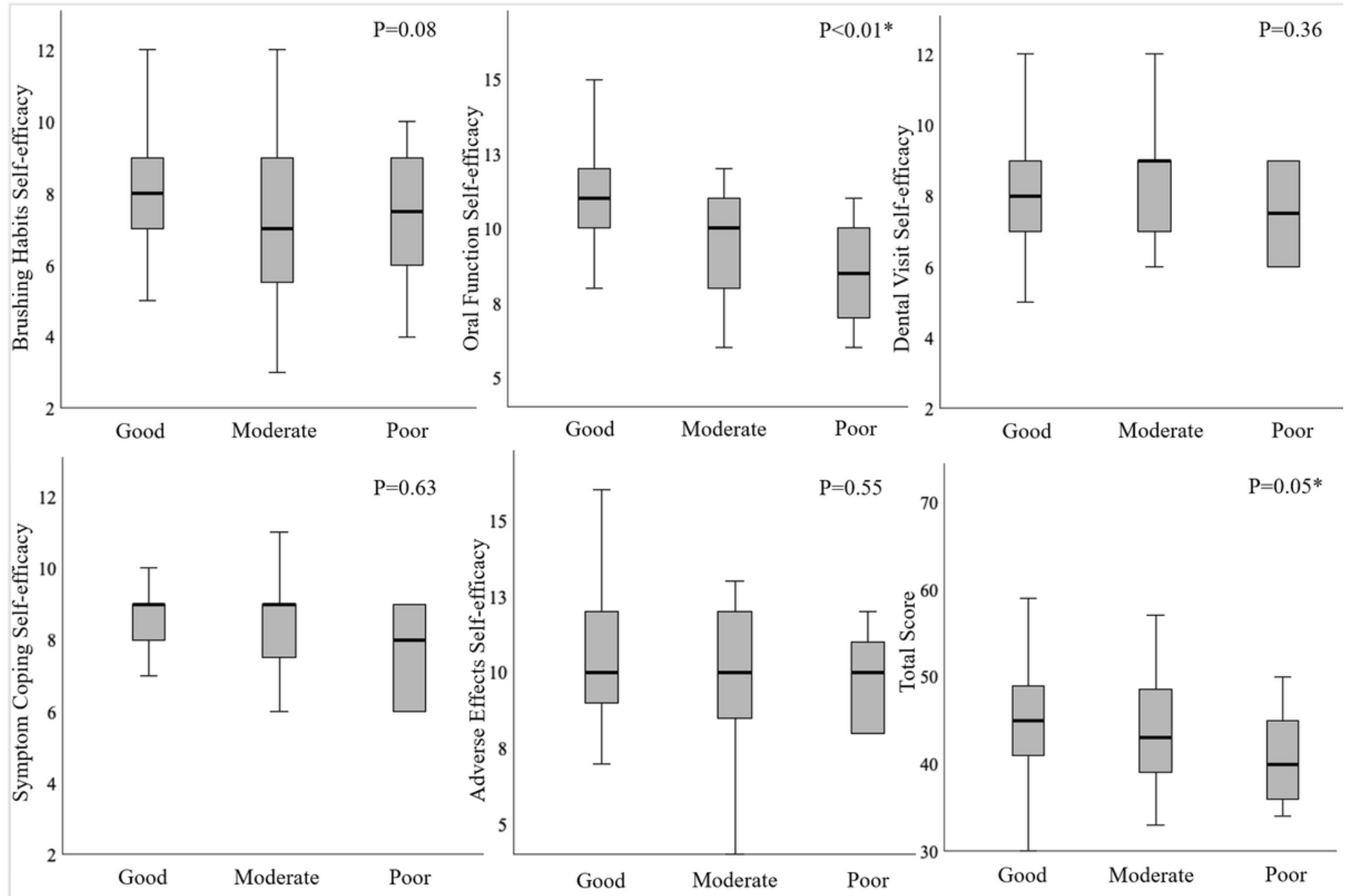

Figure 2

Stepwise correlation between the Oral Health-related Self-Efficacy Scale for Patients with Cancer and Functional Oral Intake Scale using the Jonckheere-Terpstra test

\section{Supplementary Files}

This is a list of supplementary files associated with this preprint. Click to download.

- STROBEchecklistv4combinedPlosMedicine1.docx 